\title{
LA CRÍTICA JURÍDICA RADICAL DEL DERECHO Y LA SOCIEDAD CAPITALISTA \\ Autor: Daniel Sandoval DEL SIGLO XXI
} Cervantes

Profesor-investigador del Departamento de Estudios Institucionales, Universidad Autónoma Metropolitana, Unidad Cuajimalpa. Miembro de la Asociación Nuestramericana de Estudios Interdisciplinarios de Crítica Jurídica. Correo: danielscervantes@gmail. com.

https://orcid.org/0000-0001-9978-7242

\author{
Radical Crítica Jurídica of capitalist Law \\ and Society in the 21th Century
}

Fecha de recepción: 30 de mayo de 2018

Fecha de aceptación: 30 de agosto de 2018

\begin{abstract}
Resumen:El texto constituye un esfuerzo por comprender el papel de la crítica jurídica como una crítica estructural radical al derecho y la sociedad capitalista en el siglo XXI a partir de la recuperación del materialismo histórico y dialéctico como metodología de la crítica jurídica. Para ello se estructura en cuatro partes principales, las primeras dos destinadas a analizar el papel de la violencia clasista en la construcción y funcionamiento del derecho moderno-capitalista y los mecanismos ideológicos de su naturalización e interiorización. Las últimas dos partes están destinadas a analizar el papel estratégico y táctico de la crítica jurídica y el discurso del derecho en el proceso revolucionario.
\end{abstract}

Palabras clave: Crítica Jurídica; Derecho moderno-capitalista; Violencia; Lucha de clases; Ideología.

Abstract: The text constitutes an effort to understand the role of legal criticism as a radical structural critique of capitalist law and society in the 21st century, starting with the recovery of historical and dialectical materialism as a methodology of legal criticism. To this end, it is divided into four main parts, the first two aimed at analyzing the role of class violence in the construction and functioning of modern-capitalist law and the ideological mechanisms of its naturalization and internalization. The last two parts are intended to analyze the strategic and tactical role of legal criticism and the discourse of law in the revolutionary process.

Key-words: Crítica Jurídica; Capitalist modern Law; Violence; Class Struggle; Ideology. 


\section{Naturalización de la violencia clasista en el corazón de la teoría jurídica en la economía global}

$L$ a relación entre violencia y derecho es un tema recurrente en la historia de la teoría jurídica. Sin embargo, después de la segunda guerra mundial y con la expansión del discurso de los derechos humanos en las sociedades "occidentales", se ha producido una transformación en la forma en que la teoría jurídica se aproxima a dicha relación, marcada por un desplazamiento de la concepción de la violencia en la constitución y funcionamiento del derecho moderno capitalista. En este contexto, una de las vertientes de la crítica jurídica implica la visibilización de la forma en que la violencia está presente en la conformación de lo jurídico y sus efectos como instrumento de ejercicio del poder.'

Para esta vetiente, no solamente es relevante repensar el papel fundante de la violencia en la constitución del derecho, sino en el carácter clasista que esa violencia tiene de origen y que marca el sentido de su ejercicio incluso en la actualidad, lo cual implica una instrumentalización de esa violencia como una táctica de dominación de una clase sobre otras. El carácter clasista de la violencia constitutiva del derecho capitalista es una de las claves para comprenderlo como un instrumento de dominación de clase en el capitalismo, así como también para comprender las condiciones en que los sectores y las clases dominadas disputan su sentido e incluso producen juridicidades antagónicas. ${ }^{2}$

En este sentido, se puede comprender, desde una contextualización histórica, la emergencia del concepto clásico del estado moderno como monopolización de la violencia organizada con pretensiones de legitimidad social, y la manera en que dicha monopolización no se produjo en el vacío social sino en el contexto de una clase social emergente (la burguesía) que transformó profundamente no solamente la manera dominante de las relaciones de producción (y, por tanto, también, la distribución y el consumo de mercancías), sino también las ideas dominantes a través de las cuales las diferentes sociedades se representan dichas relaciones en el capitalismo $y$, dentro de ellas, el papel que el discurso del derecho tiene en el desarrollo, justificación y legitimación de las relaciones de dominación capitalista. ${ }^{3}$ Así, la violencia clasista no tiene solamente

1- También hay vertientes de la teoría social crítica que analizan el carácter clasista de la violencia organizada en el capitalismo y sus diferentes mecanismos de despliegue -incluyendo los ideológicos o simbólicos. Véase Bourdieu, Pierre, Poder, derecho y clases sociales. Trads. María José Bernuz Beneitez, Andrés García Inda, María José González Ordovás, Daniel Oliver Lalana. Bilbao, Desclée de Brouwer, pp. 90-218, 2000; Benjamin, Walter, Para una crítica de la violencia y otros ensayos. Iluminacines IV. Trad. Robert J. Blatt Weinstein, Madrid, Taurus, 2001, p. 28-45, Sánchez Vázquez, Adolfo, Filosofía de la praxis, México, Siglo XXI,pp. 449-471 y Pereyra, Carlos, Filosofía, historia y política. Ensayos filosóficos (1974-1988), México, UNAM-FCE, 2010, pp. 27-36.

2- Parece pertinente realizar un par de aclaraciones en este punto. Por un lado, el hecho de que la crítica jurídica visibilice el carácter clasista del discurso del derecho y su organización de la violencia, analizándolo como un instrumento de dominación de clase, no significa que el discurso del derecho moderno-capitalista sea incambiable o una propiedad definitiva de las clases dominantes o que no pueda tener interpretaciones y usos subversivos (por ejemplo, como el uso alternativo del derecho); lo que significa es que la instrumentalización de dicho discurso es una tendencia general del derecho y el estado capitalistas, como fenómenos de larga duración. Por otro lado, implica que, a pesar de que el sentido del discurso del derecho es un campo de disputa, esta disputa -la lucha de clases- no se despliega en condiciones equitativas sino en las condiciones de la correlación de fuerzas existentes, en las cuales las clases dominantes son las poseedoras de los medios de producción y reproducción de la vida, entre ellos los medios discursivos de producción del derecho dominante/hegemónico. Véase: Bourdieu, P., Poder, derecho y clases sociales, op.cit., pp. 131-164, 190-214; Marx, Karl y Engels, Friedrich, La ideología alemana, Trad. Wensceslao Roces. México: Ediciones de Cultura Popular, 1974, pp. 55-83.

3- La relación entre estado y derecho moderno y la consolidación del capitalismo, con diferentes matices e ideologías, fue un tema recurrente en la teoría social, política y jurídica de finales del siglo XIX e inicios del XX. Así la encontramos en pensadores tan ideoló-

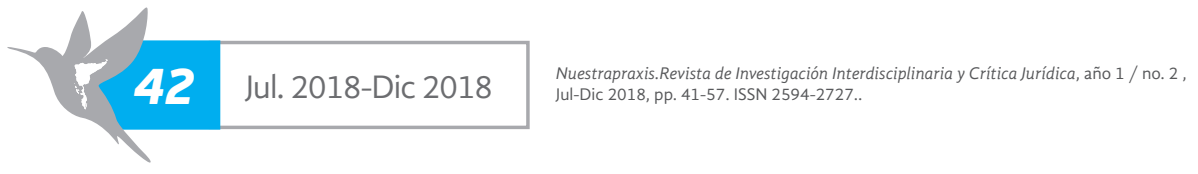


el objetivo del dominio liso y llano de una clase sobre otras, sino la producción de subjetividades dominadas que tiendan a reproducir dicha dominación con el menor recurso posible a la violencia física directa, pero con el mismo sentido. ${ }^{4}$

De acuerdo con lo anterior, resulta conveniente problematizar la relación entre violencia e ideología; por ejemplo, a través de la incorporación en los análisis del concepto de poder simbólico, ${ }^{5}$ el cual permite vincular con mayor claridad la mutua constitución entre violencia e ideología dominante y sus efectos en la producción y el desarrollo del discurso del derecho. Igualmente, es útil para pensar en diferentes planos la disputa de las clases dominadas por el derecho, sin idealizar sus condiciones y sus perspectivas; por un lado, sin olvidar al materialismo como un pilar metodológico de la crítica jurídica, en el sentido de que el derecho no puede desvincularse de las relaciones sociales que definen una sociedad ( $y$, por tanto, implican que el derecho, en sociedades capitalistas, debido a su lógica conservadora, tenderá, en términos generales, a reproducir y a legitimar las desigualdades y las explotaciones que definen a dicho régimen); ${ }^{6}$ por el otro, sin olvidar tampoco la lógica dialéctica como otro fundamento metodológico, recordando, por tanto, que el derecho constituye un elemento de la realidad concreta y su complejidad y que, en consecuencia, no puede ser comprendido de forma aislada sino desde una perspectiva de totalidad e integrando en su comprensión todas sus contradicciones. ${ }^{7}$

En este sentido, resulta importante historizar la emergencia del derecho y el estado modernos capitalistas para comprender la impronta clasista detrás de dichos mecanismos de poder, así como para diferenciar otras formas de interpretación y uso de su discurso, procedentes de subjetividades políticas antagónicas que lo disputan, si bien en condiciones de acceso desigual a las normas y agentes autorizados para manejar válidamente el discurso del derecho ${ }^{8}$-recordando que, en el capitalismo, una de las características del derecho es su carácter de discurso que dis-

gicamente disímiles como Weber y como Marx y Lenin; en la teoría jurídica de finales del siglo XIX e inicios del XX, también podríamos retomar a Hans Kelsen. Véase Weber, Max, Economía y sociedad. Esbozo de sociología comprensiva, México, Fondo de Cultura Económica, 2002, pp. 1055-1060; Kelsen, Hans, Teoría pura del derecho. 15ª ed. Trad. Roberto Vernengo, México, Porrúa, 2007, pp. 45-60; Lenin, V.I., El estado y la revolución. La doctrina marxista del estado y las tareas del proletariado en la revolución, Moscú, Editorial Progreso, 1960.

4- Sánchez Vázquez, A., Filosofía de la praxis, op.cit., p. 451; Pereyra, C., Filosofía, historia y política, op.cit., pp. 34-44.

5- En este sentido léase: “El poder simbólico, poder subordinado, es una forma transformada, es decir, irreconocible, transfigurada y legitimada, de otras formas de poder: no se puede ir más allá de la alternativa, entre los modelos energéticos que describen las relaciones sociales como relaciones de fuerzas y los modelos cibernéticos que hacen de ellas relaciones de comunicación, más que a condición de describir las leyes de transformación que rigen la transmutación de las diferentes especies de capital simbólico y en particular el trabajo de disimulación y de transfiguración (es decir, eufemización) que asegura una verdadera transubstanciación de las relaciones de fuerza haciendo desconocer-reconocer la violencia que encierran objetivamente y transformándolas así en poder simbólico, capaz de producir efectos reales sin gasto aparente de energía", Bourdieu, P., Poder, derecho y clases sociales, op.cit., pp. 98-99.

6- Marx, K. y Engels, F., La ideología alemana, op.cit., pp. 55-85; Correas, Oscar, "Acerca de la sociología jurídica: un ensayo de definición”, Crítica jurídica. Revista Latinoamericana de Política, Filosofía y Derecho, núm. 12, 1993, pp. 43-51, Capella, Juan Ramón, Fruta prohibida. Una aproximación histórico-teorética al estudio del derecho y el estado, Madrid, Trotta, 2001, pp. 20-50.

7- Lefevbre, Henri, El materialismo dialéctico, elaleph.com, 1999, pp. 9-81; Osorio, Jaime, Fundamentos del análisis social. La realidad social y su conocimiento, México, UAM-FCE, 2005, pp. 17-37 Desde la crítica jurídica sería importante recuperar las categorías de esencia y apariencia desde una perspectiva materialista histórica, estas categorías ya han sido utilizadas por ejemplo, véase Correas, Oscar, Introducción a la sociología jurídica, México, Fontamara, 2007, pp. 217-241.

8- Así, uno de los mecanismos del discurso del derecho no es, precisamente, su exclusiva posesión por una clase social, sino la construcción y control de las subjetividades que pueden interpretarlo de manera experta u oficial. Véase Foucault, Michel, Historia de la sexualidad. La voluntad del saber, México, Siglo XXI, 1971, pp. 23-65; Entelman, Ricardo, "Discurso normativo y organización del poder", Crítica Jurídica. Revista Latinoamericana de Política, Filosofía y Derecho, no. 4, 1986, pp. 109-118; Correas, Oscar, Acerca de los derechos humanos. Apuntes para un ensayo, México, Coyoacán, 2004, pp. 71-76.

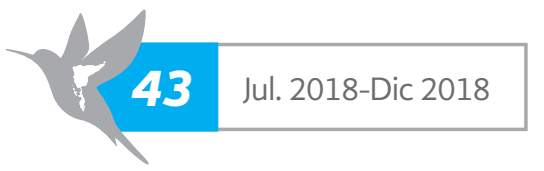


tribuye (desigualmente) el poder. ${ }^{9}$ Estos orígenes violentos del derecho y su vinculación con la consolidación de la dominación capitalista han sido suficientemente recogidos tanto por la teoría jurídica del siglo XX como por la teoría social del siglo XIX y XX, en nuestro caso nos remitimos al muy conocido pasaje de la "Acumulación originaria" de El capital. ${ }^{10}$

Ahora bien, una última consideración en cuanto a las observaciones metodológicas que contribuyan a analizar, desde la crítica jurídica, la relación entre violencia, dominación y derecho tiene que ver con la inclusión del concepto de hegemonía en los análisis y la problematización de las nociones de dirección y de consenso, en cuya formación u obtención el ejercicio de la violencia organizada a través del derecho y el estado no está ausente. De manera que ni la dirección ni el consenso implican un estado de eliminación de la violencia clasista sino una variante en sus mecanismos de ejercicio y en su visibilidad como instrumento de dominación, los cuales corresponde a la interiorización de la ideología dominante y a la consolidación de categorías de percepción que reproducen dicha ideología. ${ }^{11}$

Por otro lado, también hay que considerar que, como cualquier otro fenómeno, la relación entre violencia y derecho es contingente y que, por tanto, se transforma conforme cambian las relaciones sociales. Sin embargo, estos cambios, a pesar de su profundidad, pueden no modificar ni la estructura de la sociedad ni la del derecho; por tanto, es pertinente considerar que la relación entre capitalismo y derecho moderno no es coyuntural sino un fenómeno de larga duración. ${ }^{12}$ En este sentido, resulta conveniente pensar la manera en que las modificaciones en las correlaciones de fuerzas impactan los mecanismos y la visibilidad con que la violencia se ejerce a través del derecho. ${ }^{13}$

Así podemos plantear la siguiente hipótesis: en condiciones de no hegemonía es decir, cuando el capitalismo no ha sido la forma dominante de reproducción de la vida (por ejemplo, en el México y la América Latina de finales del siglo XIX y principios del XX), el derecho moderno tiende a mostrarse más directamente violento, puesto que no se han logrado las condiciones sociales en que el estado -y el derecho- se pueden mostrar a sí mismos como conciliadores de los conflictos de clase, sino que tienden a mostrarse como instrumentos directos de dominación,

9- Entelman, R., “Discurso normativo y organización del poder”, op.cit.

10- Marx, Karl, El capital. Crítica de la economía política. Tomo I, México, Siglo XXI, 1999, pp. 891 y ss.

11- En este sentido, la crítica jurídica debe considerar al discurso como un ejercicio de construcción de hegemonía que permite no solamente organizar de forma centralizada la violencia, sino de presentar esa violencia como algo natural y debido, y, por tanto, desplegar procesos de construcción de hegemonía. Véase Bourdieu, P., Poder, derecho y clases sociales, op.cit., pp. 165-225; Correas, O., Kelsen y los marxistas, México, Fontamara, 2004., pp. 127-161; Gramsci, Antonio, Notas sobre Maquiavelo, sobre la política y sobre el estado moderno. Madrid, Nueva Visión, 1980, pp. 51-112.

12- Si partimos del concepto de larga duración de Braudel podemos construir un vínculo entre las relaciones sociales definitorias del capitalismo (propiedad privada de los medios de producción; relaciones de producción basadas en la explotación de los seres humanos) y los elementos característicos del discurso del derecho (centralización de los medios de producción del discurso del derecho "oficial", despojo de los medios de producción de la violencia legítima); relación que no se altera con la introducción y consolidación de los derechos humanos, sino que solamente se reconfigura y transforma la manera en que la violencia organizada aparece frente al discurso del derecho. Braudel, Ferdinand, La historia y las ciencias sociales, Madrid, Alianza, 1999, pp. 52-66.

13- Así, por ejemplo, hay transformaciones del discurso del derecho que no significan cambios estructurales en las relaciones definitorias de la producción y reproducción de la vida (no alteran por ejemplo el dato esencial de la propiedad privada de los medios de producción y tendencia al despojo de las clases subalternas), si bien pueden construir un discurso -como el de los derechos humanos- que produce una contradicción aparente entre un discurso humanista del derecho y un conjunto de prácticas y relaciones sociales de despojo violento, como lo observaba Marx hace más de un siglo, más representa una forma de eufemizar la violencia del capitalismo y un mecanismo de despliegue del poder simbólico. Véase Marx, Karl, "Sobre la cuestión judía". Jaramillo, R. (Ed.). Escritos de juventud sobre el derecho. Textos 1837-1847, Barcelona, Anthropos, 2008; Bourdieu, P. Poder, derecho y clases sociales, op.cit., pp. 165-200; Correas, Oscar, Kelsen y los marxistas, op.cit., pp. 127-161.

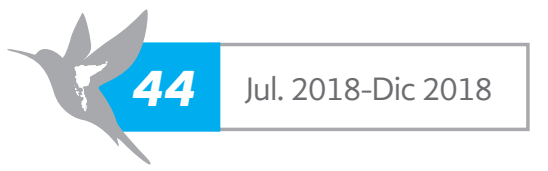


por ejemplo a través de la criminalización general de cualquier forma de oposición y a través de su participación directa a favor de las clases dominantes. ${ }^{14}$

Sin embargo, tan pronto como el régimen capitalista se convierte en la forma general de la reproducción humana en nuestras sociedades, el derecho y el estado, aunque conservando estructuralmente un papel activo en la profundización de la reproducción capitalista, lo hacen a partir de mecanismos visibles diferentes. Así, tienden a producir instancias de mediación entre clases en las cuales las clases dominadas concurren doblemente libres, en el sentido de Marx; ${ }^{15}$ pues, por un lado, lo hacen ya desposeídas tanto de los medios de producción materiales como de los jurídicos y, por tanto, en condiciones de desigualdad frente a las clases dominantes, las cuales, en términos generales, poseen no solamente los medios de producción material sino también los ideológicos (entre los cuales encontramos el discurso del derecho). ${ }^{16}$

De esta forma, el estado y el derecho dan la apariencia de ser, efectivamente, mecanismos de resolución de los antagonismos y conflictos de clase, aunque, debido al control que, en términos generales, conservan las clases dominantes, sus resoluciones tienden, estructuralmente, a no favorecer a las clases dominadas. En este sentido, el carácter de organizador de la violencia clasista del derecho tiende a invisibilizarse y el papel represivo del derecho tiende a dejar de ser percibir como su papel principal, pues la represión jurídica de ser aplicada en términos generales a cualquier oposición, pasa a ser una represión física más selectiva a ciertos sectores de oposición que cuestionan, sobre todo con sus prácticas, la estructura del régimen capitalista, para el resto de los sectores dominados la represión tiende a ejercer más bien por mecanismos más discretos pero más continuos. ${ }^{17}$

En este caso, la ideología es uno de los pilares en el papel del derecho en la dominación y en la construcción de la hegemonía capitalista. Estos periodos del derecho tienden a corresponder a lo que conocemos como estado de bienestar o estado social de derecho, en los cuales, la capacidad expansiva de la clase dominante tiende a posibilitar un discurso del derecho que incluye, redistribuyendo el ingreso, materialmente a sectores más amplios de la población, pero cuyo efecto es una más consolidada subordinación política. ${ }^{18}$

14- Esta hipótesis se relaciona tanto con la postura de Oscar Correas sobre los procesos de construcción de hegemonía, como con las ideas de Carlos Pereyra sobre los ciclos de la violencia y su relación con las reconfiguraciones del capitalismo. Véase Correas, O., Kelsen y los marxistas, op.cit. y Pereyra, C., Escritos filosóficos, op.cit.

15- "Trabajadores libres en el doble sentido de que ni están incluidos directamente entre los medios de producción como sí lo están los esclavos, siervos de la gleba, etcétera, ni tampoco les pertenecen a ellos los medios de producción a la inversa de lo que ocurre con el campesino que trabaja su propia tierra, etcétera, hallándose, por el contrario, libres y desembarazados de esos medios de producción", Marx, K., El capital, op.cit., pp. 893-894.

16- Recordando que el materialismo histórico no afirma la separación tajante entre relaciones de producción material de la vida y la reproducción ideológica de la misma, sino por el contrario una relación compleja que las hace indisociables. En este sentido, la clase dominante es la que posee los medios de producción de la vida material y los medios de reproducción de las ideas dominantes de cada época. Véase Marx, K. y Engels, F., La ideología alemana, op.cit., pp. 53-85.

17- Así por ejemplo se reproduce y extiende el carácter técnico y con parámetros técnicos e indisponibles para el intérprete en los mecanismos de control jurisdiccional de la constitución; o bien la idea del discurso del derecho, en general, como un instrumento de control del poder arbitrario, por tanto, la presuposición de la existencia de un derecho objetivo y universalizable. Véase: Huerta, Carla, Mecanismos constitucionales para el control del poder público, México, UNAM, 2010, pp. 153-175; Aragón, Manuel, Constitución, democracia y control, México, UNAM, 2002, pp. 120-170; Ferrajoli, Luigi, Garantismo. Una discusión sobre derecho y democracia, Madrid, Trotta, 2006, pp. 37-38.

18- Para el caso mexicano se puede ver Córdova, Arnaldo, La ideología de la revolución mexicana. La formación de un nuevo régimen, México, ERA, 2003, pp. 65 y ss.; Hart, John M., El anarquismo y la clase obrera mexicana 1860-1931, México, Siglo XXI, 1980, pp. 41 y ss. Véase también Gramsci, Antonio, La política y el estado moderno, España, PC Biblioteca del pensamiento crítico, 2009, pp. 203-237. 


\section{El truco de la desaparición selectiva del estado en contextos de mundialización de la lucha de clases}

Siguiendo la línea argumentativa anterior, en esta sección analizaremos la forma en que la violencia física organizada ha ido desapareciendo de las teorías jurídicas dominantes en la actualidad (como la teoría discursiva de Robert Alexy y la teoría garantista de Luigi Ferrajoli), sin que esto signifique una desaparición del papel instrumental de dominación del discurso del derecho, sino más bien una transformación de los mecanismos a través de los cuales opera. En este sentido, esta transformación de sus mecanismos, por un lado, ha sido posibilitada por la pérdida de fuerza de las clases subalternas en la toma de decisiones políticas fundamentales, es decir, un cambio en la correlación de las fuerzas sociales desfavorable para las clases subalternas; mientras que, por otro, tiene como efecto una profundización de la construcción de hegemonía de la clase dominante.

La transformación jurídica fundamental en la que estos cambios se observan es el concepto de estado constitucional de derecho, ${ }^{19}$ el cual se presenta como una síntesis tanto de la emergencia y consolidación del concepto normativo de constitución-como los cambios organizativos en los agentes jurídicos asociados- como en la idea del estado social de derecho. El sentido del concepto de estado constitucional y social de derecho implica, por un lado, la construcción de un acuerdo mínimo universal sobre las condiciones sociales de reproducción de la vida y, por el otro, que el desarrollo de la acción del estado tenderá a realizarse limitado o controlado por el derecho, considerado como un control técnico y no sujeto a la conflictividad social. ${ }^{20}$

Por un lado, el estado social de derecho es un elemento más antiguo conformado durante la primera mitad del siglo XX, marcado por la capacidad del estado de incluir -aunque de manera políticamente subordinada- a sectores sociales cada vez más amplios en la esfera del consumo, sin modificar de manera radical la estructura capitalista del proceso de producción. En este sentido, el estado social de derecho ha sido una pieza fundamental para consolidar al discurso del derecho como una instancia de resolución de los conflictos sociales derivados de la división clasista de nuestras sociedades. Sin embargo, no ha transformado las relaciones sociales definitorias del régimen capitalista, pues, en lugar de socializar los medios de producción -aunque sea de manera parcial - ha producido su concentración creciente, sobre todo en las décadas de los ochenta y noventa, en que el estado social de derecho ha dado pie a la emergencia de las políticas que conocemos como neoliberales. Así, el estado social de derecho debe ser analizado como una condición necesaria para la reconfiguración de la dominación y construcción de hegemonía capitalista, y no como una ruptura o una forma de contrapoder frente a éstas. ${ }^{21}$

Esta transformación del papel del derecho debe ser entendida en el marco de los cambios

19- Ferrajoli, Luigi, “Pasado y futuro del estado de derecho”, Revista Internacional de Filosofía Política, no. 17, 2001, pp. 31 -46.

20- Ibidem.

21- Así, por ejemplo, existen análisis sobre la política del New Deal en Estados Unidos, así como también del periodo industrializador en México, y en diversos países de América Latina. En el caso de México, la constitución de 1917 configuró un nuevo papel del estado y el derecho como mediadores, y por tanto como mecanismos de invisilbilización, de los antagonismos y conflictos de clase, así, el estado social constituye una de las condiciones necesarias para la reconfiguración del capitalismo en México en condiciones de agudización de la lucha de clases. En este proceso la emergencia e institucionalización (estructuralmente precaria, selectiva y políticamente subordinante) los derechos sociales tuvieron un papel esencial. Véase Sandoval Cervantes, Daniel, Apuntes para una crítica de la epistemología del derecho contemporáneo, Tesis doctoral, México, Facultad de Derecho, Universidad Nacional Autónoma de México, 2013, pp. 132-260. 
en la concepción de la constitución misma. Así, la emergencia del concepto normativo de constitución es el resultado de un proceso de cambio jurídico profundo que ha modificado tanto las formas de justificar y argumentar las decisiones sobre el discurso del derecho como los agentes centrales encargados de realizarlas. ${ }^{22}$ En este sentido, es a través de la justicia constitucional y la figura del tribunal constitucional que el discurso del derecho y el discurso jurídico especializado han transitado hacia una tecnificación jurídica de las decisiones en torno a la aplicación normativa de las constituciones, de tal manera, que a la interpretación del texto constitucional realizada por un juez constitucional se le adjudica, desde la teoría jurídica dominante, la capacidad de decidir técnicamente sobre el sentido de sus normas. ${ }^{23}$ Así se ha construido y consolidado la idea de un control jurídico más allá de la conflictividad social y política producida por una sociedad dividida en clases.

Estas transformaciones deben ser examinadas en el contexto social, político y económico en que han aparecido para poder evaluar los efectos que tienen en la construcción de hegemonía capitalista y en la transformación de sus mecanismos de dominación. En este sentido, tomaremos el caso mexicano para estar en condiciones de contextualizar de manera más concreta dichas transformaciones.

Como se sabe, la emergencia del estado social de derecho [del estado de bienestar] en México, como en la mayor parte del mundo, se presenta en la primera mitad del siglo XX, consolidándose -con sus limitaciones - hacia la mitad de dicho siglo. En cuanto a nuestra región, esta consolidación se lleva a cabo en condiciones favorables de la coyuntura política y económica internacional que permitieron procesos de industrialización más comprensivos que aquellos que fueron posibles durante el siglo XIX en América Latina enfocados, principalmente, a la extracción y comercialización al exterior de materias primas, lo que se denominado como patrón primario exportador. Dicho modelo económico tuvo como correlato un régimen político y jurídico marcado por un estado represivo y que, tendencialmente, adoptaba una clara postura dentro de la lucha de clases, por ejemplo, ilegalizando las organizaciones de trabajadores y reprimiendo sus actividades; como también legalizando el despojo masivo de tierras -e intentando exterminar formas colectivas y no capitalistas de posesión de la tierra, aún dominantes en gran parte del siglo XIX - para la construcción de infraestructura (principalmente el ferrocarril) necesaria para la integración de nuestros países en la economía mundial, en condiciones de dependencia. ${ }^{24}$

En el trasfondo de ese posicionamiento abiertamente clasista y represor del estado en el siglo XIX sucedieron, en los inicios del siglo XX, diversas revoluciones sociales -las cuales, se caracterizaron por exigencias de inclusión política en sus inicios, pero que, con diferentes grados de intensidad, fueron incluyendo exigencias sociales y económicas en el marco de la incorporación de las clases dominadas-, el caso de la revolución mexicana, iniciada en 1910, es quizá el más claro. En este contexto de agudización de la lucha de clases -marcada por el ascenso de la ideología radical (anarquista y marxista) en las organizaciones de trabajadores y campesinos- emerge el estado social, por un lado, como el producto de la lucha de las clases subalternas, pero, también, como la consolidación de la capacidad de dirección de las sectores modernizadores de la clase

22- El carácter normativo de la constitución, véase Mora-Donato, Cecilia, El valor de la constitución normativa, México, UNAM, 2002, p. 19 y ss.

23- En este sentido, opera en la mayor parte de la teoría jurídica dominante una "despolitización" de la interpretación jurisdiccional considerándola como una tendencialmente actividad objetiva y basada en conocimientos jurídicos técnicos y no en la oportunidad y justificación política, véase Aragón, M., Constitución, democracia y control, op.cit., pp. 120 y ss.

24- Véase Osorio, Jaime, Teoría marxista de la dependencia, México, ITACA, 2016, pp. 277-293; Pereyra, C., Escritos filosóficos, op.cit., p. 36; Marini, Ruy Mauro, Dialéctica de la dependencia, México, ERA, 1989, pp. 14 y ss. 
burguesa emergentes, que, en términos generales, mostraban un antagonismo relativo frente a las facciones oligarcas de la antigua burguesía terrateniente. ${ }^{25}$

Ahora bien, la consolidación de la dirección de la moderna burguesía ha sido una de las condiciones para la construcción de la hegemonía en el capitalismo actual, y en dicha consolidación, el nuevo papel del estado y el derecho como mediadores de los antagonismos de clase fue fundamental. Por un lado, el carácter expansivo de la moderna burguesía permitió una articulación con las clases dominadas y, por tanto, la creación de una fuerza social lo suficientemente poderosa capaz de modificar el patrón de reproducción. Por el otro lado, esta articulación, al final del proceso de transformación, consolidó la dirección de la moderna burguesía, no solamente a través de la violencia física -cuando fue necesario recurrir a ella, en el caso mexicano, por ejemplo, en la disputa militar entre el ejército constitucionalista frente tanto al ejército libertador del sur, comandado por Emiliano Zapata, como también frente a la División del Norte, comandada por Francisco Villa-, sino que, principalmente, permitió transformar la forma en que se organizaba y ejercitaba la violencia a través del uso del derecho, marcada por una mayor selectividad en su aplicación acompañada de una inclusión material parcial y subordinada de las clases subalternas. ${ }^{26}$

De tal manera, la emergencia del estado social de derecho es el resultado momentáneo de la agudización de la lucha de clases en los últimos años del siglo XIX y los primeros del siglo $X X$, que marca una transformación profunda, pero no estructural, en el papel del discurso del derecho en la reproducción del capitalismo, una tendencia hacia una construcción del derecho como mediador de los conflictos de clases con un acceso desigual y clasista a la determinación de su discurso y los efectos de éste. Esta transformación fortalece el momento expansivo de la clase burguesa en ascenso y, en este sentido, su capacidad de dirección, sin que signifique el fin de la violencia clasista del capitalismo, sino el tránsito a formas de dominación más discretas pero más continuas y efectivas. ${ }^{27}$ Por un lado, debido a que el derecho y el estado se consolidaron como mecanismos de resolución de conflictos colocados por encima de la lucha de clases -principalmente gracias a la implementación de procesos redistributivos y de prestación de servicios a través del estado, como la salud, la educación y la vivienda-; mientras que, por el otro, a pesar de la dilución del carácter abiertamente clasista y represor de los estados liberales de finales del siglo XIX, fortaleció la idea del derecho como un mecanismo de organización centralizada de la violencia física a favor del bien común, y por tanto, como una forma de controlar y racionalizar socialmente el poder, antes ejercido de manera arbitraria contras las clases dominadas. ${ }^{28}$ Sin embargo, estas modificaciones no significaron la transformación estructural de nuestras sociedades, $y$, por consiguiente, no implicaron la superación de las sociedades divididas en clases, sino solamente la modificación de la manera en que opera dicha división y la apertura de una fase distinta en la lucha de clases.

25- Gilly, Adolfo, La revolución interrumpida, México, ERA, 1994, pp. 124 y ss.; Córdova, Arnaldo, La ideología de la revolución mexicana. La formación de un nuevo régimen, op.cit., pp. 180-220.

26- Como fundamento de dichos procesos se encuentra la "institucionalización de la revolución" que culminó durante el gobierno cardenista, que consistió en el afianzamiento del estado y el derecho como mecanismos "pacíficos" de resolución de los conflictos sociales a través de la institucionalización definitiva de las fuerzas armadas, la organización del partido hegemónico y de la democracia partidista, la subordinación política de buena parte de las organizaciones de las clases subalternas, véase Córdova, Arnaldo, La política de masas del cardenismo, México, ERA, 2010, pp. 27 y ss.; León, Samuel y Marván, Ignacio, La clase obrera en la historia de México. En el cardenismo (1934-1940), México, Siglo XXI, 1985, pp. 15 y ss.

27- Foucault, Michel, Vigilar y castigar. Nacimiento de la prisión, trad. Aurelio Garzón del Camino,, México, Siglo XXI, 2002, pp. 211 y ss.

28- Véase Sandoval Cervantes, D., Apuntes para una crítica de la epistemología del derecho contemporáneo, op.cit., pp. 263 y ss. 
En esta nueva fase, el discurso del derecho tiende a tener un papel más discreto pero más continuo y efectivo en la resolución de los antagonismos de clase dentro de los límites del capitalismo. Lo anterior, puesto que, por un lado, su presencia es mayor en la regulación de la vida, y dentro de ella de la vida cotidiana, como presupuesto mismo de su papel en los mecanismos redistributivos; por el otro, porque, debido a una efectividad estructuralmente desigual de sus sectores, dichos sectores participan de manera diferenciada en la construcción de la eficacia política del derecho en el régimen capitalista, permitiendo que el discurso del derecho, por un lado, construya un mundo ideal de normas que tiende a presentar las relaciones sociales como efectivamente no lo son (el salario como retribución igual por el trabajo realizado, la constitución como un consenso de normas de convivencia que regulan efectivamente nuestras sociedades), en todo caso como un ideal que puede ser reconstruido políticamente por las clases subalternas a través del uso alternativo del derecho hasta ciertos límites; mientras que, también, el discurso del derecho contiene sectores que son invocados para mantener el orden capitalista, por ejemplo, a través del "estado de derecho" en relación con la inversión privada y la necesidad de genera condiciones de "certidumbre jurídica" para dichas inversiones, el discurso del derecho es utilizado para justificar la violencia de clase organizada a través del estado en contra de los movimientos y comunidades que antagonizan con el modo de producción capitalista. ${ }^{29}$

Así, el poder que se ejerce instrumentalmente a través del derecho tiene un componente simbólico fuerte, lo cual no significa su desvinculación de la violencia clasista organizada, sino su presentación de forma transfigurada, su naturalización como parte de un proceso de construcción de hegemonía, en el cual tiende a obscurecerse el origen y el carácter clasista del discurso del derecho moderno. En este proceso de eufemización de la violencia organizada, la construcción del derecho como un sistema unitario de normas, tiende a oscurecer el hecho de que no existe el "Derecho" en general, sino sectores normativos que concurren en la formación del ideal jurídico y que, en el capitalismo, concurren de forma desigual; a grandes rasgos, por un lado, las normas que tienden a cristalizar los intereses de las clases subalternas (por ejemplo, los derechos sociales, colectivos y del medio ambiente), por otro lado, las normas jurídicas que tienden a vehiculizar los intereses de las clases dominantes (por ejemplo, las normas relacionadas con la certidumbre de la propiedad privada, incluyendo las normas penales).

Así, las primeras tienden a no ser definitorias en la construcción del sentido común sobre el concepto de "estado de derecho" y más bien tienen una eficacia política basada en su capacidad ideológica y no tanto en su efectividad estructural, sobre todo en las sociedades dependientes como las latinoamericanas. Las segundas, parecen aprovechar la capacidad ideológica de las primeras, pues son relevantes para la reproducción del régimen capitalista, no tanto por generar consensos en la mayor parte de la población sino por su efectividad, incluyendo los casos en que deben ser aplicadas recurriendo a la violencia organizada estatal y jurídicamente. Es importante considerar esta participación desigual de los distintos sectores normativos ( $y$ el origen clasista de dicha desigualdad) para comprender el oscurecimiento del carácter clasista de la violencia estatal y la desaparición selectiva del estado, experimentada a partir de la década de los ochenta. ${ }^{30}$

29- Correas, Oscar, Teoría del derecho, México, Fontamara, 2004, pp. 127-194; Jeammaud, Antoine, "En torno al problema de la efectividad en el derecho", Crítica Jurídica. Revista Latinoamericana de Política, Filosofía y Derecho, no. 1, 1984, pp. 5-15, Bourdieu, P., Poder, derecho y clases sociales, op.cit., pp. 88-99.

30- Desaparición selectiva del estado que es, más propiamente, una reconfiguración del papel del estado y el derecho en la reproducción de la vida; pues, más que desaparecer o "debilitarse", el estado se reacomoda y adquiere lógicas y finalidades distintas a las del estado social. Osorio, Jaime, “El estado en el capitalismo dependiente”, pp. 277-296, en Osorio, Jaime, Teoría marxista de la dependencia, op.cit.; Capella, Juan-Ramón, Fruta prohibida: una aproximación histórico-teorética al estudio del derecho y del estado, op.cit., pp. 257-291 


\section{3.-Destruir para construir: el papel de la crítica jurídica destructiva en el capitalismo del siglo XXI}

En todo caso, la desaparición selectiva del estado y el derecho, y la aparición y consolidación del poder simbólico ejercido a través del discurso del derecho, no pueden ser vistas como una transformación social ocurrida en el vacío o como producto de la progresiva humanización de la sociedad y su derecho, sino como producto de la transformación de la correlación de fuerzas a nivel mundial; es decir, la lucha de clases continua siendo el motor de la historia y, dentro de ésta, el motor de las transformaciones en la concepción, construcción y los efectos del discurso del derecho. En este caso, la crítica jurídica debe analizar no solamente los cambios en el discurso del derecho y el discurso jurídico, que apuntan hacia un avance progresivo de los derechos humanos y una construcción, si bien conflictiva, de un estado de derecho internacional; ${ }^{31}$ sino, más bien, a las condiciones materiales en que esos discursos son producidos y los efectos que tienen en éstas: sociedades cada vez más desiguales, normatividades que tienden a ser cada vez menos democráticas (incluso bajo los estándares de la democracia representativa liberal), un retroceso en la efectividad (inclusive en las características formales) de los derecho sociales (sobre todo los laborales y los relacionados con el territorio).

En este contexto, la progresividad del discurso de los derechos humanos no puede comprenderse solamente a partir de su apariencia, como si existiera por encima de la lucha de clases, sino que, por el contrario, resulta necesario analizar dicha progresividad en el contexto de la lucha de clases actual, y sin perder de vista la relación entre el derecho y el capitalismo en la larga duración. Una perspectiva desde la larga duración, por un lado, permite explicar las características definitorias de la relación entre el capitalismo y el derecho moderno; mientras que, por el otro, esta misma distinción permite analizar las condiciones en las cuales las transformaciones de la sociedad capitalista han influido en las los cambios del discurso del derecho y del discurso jurídico, sin modificar su relación fundamental, es decir, permite diferenciar las variaciones que no significan o no provienen de una transformación estructural de la sociedad y, por tanto, no implican una transformación estructural en las causas y los efectos del discurso del derecho, de los cambios que sí implicarían una discontinuidad histórica del régimen capitalista. ${ }^{32}$

De esta manera, la crítica jurídica constituye una perspectiva que, al explicar las relaciones continuas entre el régimen capitalista y el derecho moderno va más allá de la apariencia del discurso del derecho para indagar la esencia de la relación entre capitalismo y derecho en la modernidad capitalista. Visibilizando dichas relaciones en la larga duración permite también denunciar la forma en que el progreso humanista en el discurso de los derechos humanos constituye, no una especie de contrapoder frente al capitalismo, sino la emergencia y constante refinación de mecanismos de construcción de hegemonía dentro de la lucha de clases, en condiciones en que las clases subalternas han perdido capacidad de organización y, también, fuerza ideológica en

31- Por ejemplo, Ferrajoli, Luigi, "Pasado y futuro del estado de derecho", op.cit., pp. 31-46 y en Alexy, Robert, El concepto y la naturaleza del derecho. Trad. Carlos Bernal Pulido. Madrid: Marcial Pons, 2008, pp. 87-90; Alexy, Robert, Derecho y razón práctica. México: Fontamara, 2006, pp. 47-60.

32- Véase Braudel, Ferdinand, La historia y las ciencias sociales, op.cit. 
la construcción de la conciencia de clase. ${ }^{33}$ En este sentido, por ejemplo, se puede vincular las transformaciones del derecho con los ciclos de la violencia en el capitalismo y pensar esta fase del desarrollo del discurso del derecho como una transformación en condiciones de mayor capacidad hegemónica de las clases dominantes sobre las subalternas. ${ }^{34}$

En este sentido también, la crítica jurídica contribuye a construir explicaciones materialistas - puesto que van más allá de la apariencia del discurso del derecho y analizan las relaciones sociales de producción de la vida material en que dicho discurso se produce-, así como también un análisis dialéctico - puesto que implica analizar la relación entre las relaciones sociales definitorias del régimen capitalista y las características esenciales del discurso del derecho moderno. En estas condiciones, la crítica jurídica implica una explicación de los cambios en las condiciones de estatalidad y de juridicidad dentro del horizonte del régimen capitalista y, por tanto, un análisis que contribuye a su destrucción a partir de la comprensión rigurosa de su funcionamiento.

Esta tarea destructiva o negativa de la crítica jurídica no solamente representa una postura académico-científica que implica un análisis riguroso de las sociedades capitalistas y, como parte de ella, del derecho moderno; sino que también implica una posición -con diversos maticespolítica que se plantea una discusión en torno a qué postura tomar frente al derecho moderno capitalista como parte de la estrategia revolucionaria. ${ }^{35}$ El dilema se encuentra en la forma en que el derecho moderno -no solamente capitalista por su origen histórico, como un dato simple del pasado, sino por su intricada relación con los mecanismos de poder y construcción de hegemonía del capital- puede o no ser utilizado para la destrucción y superación de la sociedad capitalista. En este contexto, se trata tanto de una discusión sobre la estrategia en general, como las tácticas dentro de la lucha de clases.

Así, en cuanto a la estrategia, la discusión se sitúa, en términos generales, sobre el posible carácter transformador del derecho moderno; en cuanto a la táctica, implica una discusión sobre cómo es posible utilizar parte del discurso del derecho moderno para avanzar en la lucha de clases, o bien, para generar mejores condiciones para las clases subalternas dentro de esa lucha. En la primera discusión, la cuestión gira en torno a un análisis de las formas en que se ejerce el poder en el capitalismo y la manera en que el derecho moderno puede contribuir a construir condiciones de socialidad no capitalista, principalmente a partir de la utilización del discurso de los derechos humanos; en cuanto a ello, la principal dificultad constituye en la posibilidad de fragmentar un discurso, como el del derecho, íntimamente imbricado en las relaciones sociales que definen al capitalismo, precisamente para destruir dicho régimen.

En este sentido, parece imposible que imponer los sentidos dominante del derecho y el estado moderno sean el objetivo de la estrategia revolucionaria, puesto que, a final de cuentas, la historia de las revoluciones sociales, las cuales lograron redefinir los fundamentos explícitos del derecho a través de la promulgación de nuevas constituciones producto de la lucha social (como el caso mexicano en 1910-1917, o los casos boliviano, ecuatoriano y venezolano en la vuelta del

33- Una línea de análisis iniciada durante el siglo XIX por Marx, véase Marx, Karl, "Sobre la cuestión judía”, op.cit., pp. 127-163.

34- Sánchez Vázquez, A., Filosofía de la praxis, op.cit., p. 451; Pereyra, C., Filosofía, historia y política, op.cit., pp. 34-44.

35- Estrategia que debe evaluar el papel de las normas jurídicas en el proceso revolucionario y su relación con la lucha de clases en procesos históricamente determinados. Por un lado, evaluar en qué condiciones y con qué alcances, el uso del discurso del derecho moderno-capitalista puede ser útil para generar un avance en el proceso revolucionario, por ejemplo, profundizando la organización autónoma de las clases subalternas y su articulación frente a las clases dominantes; y en qué condiciones puede implicar una subordinación política frente al estado y las clases dominantes, lo que provoca la desarticulación y la inmovilización de las clases subalternas. En este sentido, la tarea negativa de la crítica jurídica es visibilizar el papel conservador del discurso del derecho moderno-capitalista y sus límites tácticos y estratégicos en la lucha revolucionaria. 
siglo XX y el XXI) han demostrado que la redefinición del discurso del derecho, inclusive a nivel constitucional, lo más que puede ofrecer son nuevos horizontes para profundizar la revolución y la transformación de las relaciones sociales, pero que, a final de cuentas, la estrategia revolucionaria no consiste en tomar el estado y el derecho, sino en transformar las relaciones sociales que definen nuestras sociedades, lo cual no se puede realizar a través de decretos, sino a través de la transformación de las relaciones de producción de la vida material, de las cuales, si bien, el discurso del derecho forma parte, no puede definirlas. ${ }^{36}$

En cuanto a la táctica, ${ }^{37}$ la discusión no se centra en pensar la capacidad transformacional del derecho moderno, sino, a las formas específicas en que ciertas normas o sectores de normas de ese discurso se pueden utilizar tácticamente para avanzar en el movimiento revolucionario. El uso táctico del discurso del derecho moderno implica, por un lado, un reconocimiento de la importancia de su discurso para la reproducción de la vida material, es decir, como un instrumento de la lucha de clases; por otro, el reconocimiento de los límites transformacionales del derecho moderno-capitalista, en el sentido de que implica el reconocimiento de que la tendencia general es que sus mecanismos interpretativos y de aplicación ( $y$, por tanto, su relación con la organización de la violencia) impongan condiciones favorables para la profundización (y en algunos casos la reconfiguración, en condiciones de agudización de la lucha de clases) de la dominación y la construcción de hegemonía del capitalismo.

Así, tanto el uso alternativo el derecho como el positivismo de combate se refieren a tácticas que utilizan, de forma subversiva -en tanto con una subjetividad política antagónica con el capital - normas reconocidas como parte del derecho moderno capitalista, no con el objetivo de transformar la sociedad y el derecho capitalista desde dentro (utilizando el mismo derecho capitalista para hacerlo) sino como una forma de visibilizar, articular y movilizar las exigencias de las clases subalternas, principalmente en temas relacionados con lo que se presenta como derecho sociales y colectivos, así como los casos de criminalización y judicialización de la protesta social. ${ }^{38}$ En todo caso, ambas prácticas reconocen que el objetivo estratégico no es construir una

36- En este sentido la crítica jurídica no deja de ser una crítica implacable a la sociedad y el derecho capitalista, y por tanto, al estado moderno-capitalista. El objetivo estratégico de la revolución no es la toma del estado, sino la transformación radical y estructural de la sociedad: la superación del capitalismo a nivel mundial.

37- Así, en cuanto al uso táctico del discurso del derecho, la crítica jurídica debe ser cuidadosa, por una lado, de contribuir al avance del proceso revolucionario utilizado todos los instrumentos disponibles -entre ellos el discurso del derecho moderno capitalista, cuando sea posible-, evaluando la correlación de fuerzas en cada sociedad concreta y a nivel mundial; pero, por el otro, debe ser cuidadosa de no sacrificar el objetivo de la revolución (terminar con división en clases que determina las relaciones de explotación en el capitalismo) a los objetivos posibles en el corto plazo, adoptando posturas reformistas. Véase Bambirra, Vania, Dos Santos, Theotonio, La estrategia y la táctica socialistas de Marx y Engels a Lenin, México, ERA, 1980, pp. 10 y ss.

\footnotetext{
38- Por ejemplo, una utilización subversiva de los derechos procesales en los casos de criminalización de la protesta social, lo cual no implica la creencia de que el derecho tiene un valor moral positivo, sino, la identificación de las normas jurídicas como una de las formas políticas que pueden ser eficientes para lograr la libertad de los presos políticos en las condiciones de la correlación de fuerzas de nuestras sociedades. En el mismo caso podemos considerar la exigencia de legislación y protocolos en contra de la desaparición forzada, su exigencia no implica la creencia de que dicha normatividad evitará la reproducción de la desaparición forzada, pues ésta es causada por la reproducción de las relaciones capitalistas dentro de las cuales actúan las fuerzas de seguridad estatales y paraestatales. De la misma manera, el uso alternativo de los derechos humanos -especialmente los sociales y los colectivos- no implica la creencia de que con el reconocimiento de dichos derechos se ha logrado la transformación social, sino la identificación de éstos como una condición que permite profundizar la lucha de clases y generar, parcialmente, mejores condiciones sociales y políticas. Véase Melgarito Rocha, Blanca Estela, "La criminalización de la protesta y el modelo civilizatorio moderno en América Latina. El caso de Minera San Xavier y Pedro Rebolloso", pp. 49-97 y Melgarito Rocha, Alma Guadalupe, "Notas para un uso alternativo del derecho: el proceso penal del anarquista insurreccionalista mexicano Mario Antonio López Hernández", pp. 157-183, en Correas, Oscar; Melgarito Rocha, Alma y Sandoval Cervantes, Daniel, Criminalización de la protesta social y uso alternativo del derecho, México, UNAM-CEIICH-DGAPA/Coyoacán, 2014; de la Torre Rangel, Jesús Antonio, El derecho como arma de liberación en América Latina. Sociología jurídica y uso alternativo del derecho, San Luis Potosí, CENEJUS, 2004, pp. 65-130.
} 
nueva interpretación del derecho moderno capitalista, sino utilizarlo para avanzar o para generar mejores condiciones para el movimiento revolucionario. De manera que pueden ser entendidos como tácticas negativas o destructivas de la praxis revolucionaria frente a la sociedad y el derecho capitalistas.

Otras sociedades, otras mundializaciones y otros derechos: la visibilización de alternativa como tarea de la crítica jurídica contemporánea y la disputa por las revoluciones sociales, simbólicas y paradigmáticas

Así, por un lado, las discusiones acerca del papel estratégico y táctico del discurso del derecho moderno implican una visibilización de la tendencia de éste a ser instrumentalizado como un mecanismo de dominación y construcción de hegemonía capitalista, como una de las condiciones necesarias para la consolidación y profundización del capitalismo como régimen mundial. Si bien esta perspectiva de la crítica jurídica tiende a señalar su tarea analítica negativa de descripción de las formas en que el derecho del discurso del derecho moderno se articula y complementa la dominación capitalista; se mantiene la idea subyacente de la importancia de la normatividad, en general y no necesariamente aquella impuesta por el derecho moderno, en la historia de la organización humana y, por tanto, no es un elemento que debe ser excluido del movimiento revolucionario.

En este contexto, es que una de las tareas de la crítica jurídica es explicar las transformaciones sociales y normativas -y dentro de las normativas las jurídicas - que implicaría una superación de la sociedad y el derecho capitalista; esta discusión resulta esencial para visibilizar la diferencia entre la reforma (que incluye la promulgación de nuevas constituciones no acompañadas de una transformación radical del estado y la sociedad) y revolución. Mientras que ciertas reformas pueden tener un uso táctico para la praxis revolucionaria, el cual debe ser visibilizado y analizado por la crítica jurídica -por ejemplo, por medio del concepto de uso alternativo del derecho- ${ }^{39}$ en el entendido que, mediante dicho uso táctico puede contribuir a mejorar las condiciones materiales de las clases subalternas, o bien, permitir movilizar sus exigencias por medios que contribuyan a su difusión y su capacidad de construir una hegemonía contraria a la capitalista.

Lo cierto es que la reforma no es el objetivo estratégico final de la praxis revolucionaria y, por tanto, una de las tareas de la crítica jurídica es, precisamente, diferenciar entre la reforma jurídica y la praxis jurídica revolucionaria. Siendo la reforma jurídica un conjunto de modificaciones en el discurso del derecho que, si bien pueden significar una mejoría en las condiciones de disputa de las clases dominadas, no implican una superación de la sociedad y la legalidad capitalista, y por tanto, mantiene y tiende -en términos generales- a reproducir las relaciones sociales que definen al régimen capitalista. ${ }^{40}$

En este sentido, la tarea positiva de la crítica jurídica consiste en, precisamente a partir de la identificación de las condiciones y el uso táctico de las reformas jurídicas, distinguir éstas de la praxis jurídica revolucionaria, como aquél conjunto de prácticas jurídicas $-y$, por tanto, parte de las relaciones sociales tendencialmente no capitalistas que las causan y sobre las cuales dichas prácticas tienen efectos- que no solamente pueden ser usadas para mejorar las condiciones de lucha de las clases subalternas sino para construir una sociedad no divida en clases $y$, por tanto, una sociedad no capitalista.

\footnotetext{
39- Para de la Torre Rangel, el uso alternativo del derecho "[...] constituye las diversas acciones encaminadas a que toda juridicidad (normatividad, derechos subjetivos, ideas y concretizaciones de justicia) sea usada al servicio de los pobres como sujeto histórico, tanto ante las instancias judiciales y administrativas del Estado, como por ellos mismos en sus relaciones comunitarias creando y recreando la solidaridad", de la Torre Rangel, J.A., El derecho como arma de liberación en América Latina. Sociología jurídica y uso alternativo del derecho, op.cit., p. 100.

40- En todo caso pueden existir condiciones concretas en las cuales la reforma pueda ser una táctica revolucionaria, pero la reforma no puede sustituir a la revolución como objetivo estratégico final. Bambirra y Dos Santos, Theotonio, La estrategia y la táctica socialistas de Marx y Engels a Lenin, op.cit..
} 
En este contexto, la tarea de los análisis realizados desde la crítica jurídica no es simplemente especulativa o un acto de adivinación sobre cuál sería el papel de un derecho hipotéticamente no capitalista en la construcción de una sociedad imaginaria no capitalista. Al contrario, la tarea es visibilizar aquellas comunidades, movimientos y organizaciones de las clases subalternas que, en su construcción de relaciones no capitalistas, construyan también normatividades subversivas, que antagonicen con el núcleo definitorio del derecho moderno capitalista (la imposición y la defensa de la propiedad de los medios de producción y, por tanto, la reproducción de la sociedad divida en clases).

Estas praxis normativas revolucionarias existen en diferentes lugares de nuestro planeta; en el pensamiento jurídico crítico (y dentro de éste, en la crítica jurídica nuestramericana) el énfasis se ha puesto especialmente en el derecho propio de las comunidades indígenas en la defensa de sus territorios y formas sociales de reproducción, cuando éstas antagonizan con aquellas que definen al régimen capitalista. A estos análisis, con sus diferencias en matices y posturas, se les ha denominado como pluralismo jurídico, ${ }^{41}$ dentro de la crítica jurídica, específicamente como pluralismo subversivo, ${ }^{42}$ resaltando la característica de que sus normas -al provenir de relaciones sociales no capitalistas - antagonizan con la normatividad del derecho moderno capitalista, especialmente en cuanto a la propiedad de la tierra -y los medios de producción-y, por tanto, en la forma en que se organiza (material e ideológicamente) la reproducción de la vida.

Sin embargo, la crítica jurídica también podría visibilizar la praxis jurídica revolucionaria en organizaciones y movimientos que disputan la hegemonía al régimen capitalista y que establecen relaciones entre sus miembros y con miembros de otros colectivos que tienden a trastocar la esencia del régimen capitalista. Por ejemplo, organizaciones campesinas que, si bien no forman parte de comunidades indígenas y no cuentan con una matriz cultural diferente a la moderna-capitalista, si han intentado reproducir la vida de una forma distinta; por ejemplo, por medio del trabajo cooperativo colectivo. ${ }^{43}$ Otro ejemplo, podrían ser las organizaciones de trabajadores que intentan construir relaciones de producción desde una perspectiva distinta a la capitalista, ya sea a través de la economía solidaria, del trabajo cooperativo o la recuperación/ocupación de empresas.

\section{Conclusiones}

Analizar el papel de la violencia y los mecanismos ideológicos de naturalización e interiorización constituye uno de los aspectos más importantes para comprender el papel del derecho moderno en la reproducción y profundización del capitalismo; no solamente en cuanto al papel negativo de

\footnotetext{
41- "En algunos casos, de manera diferente que en el caso de la simple alternatividad [en el cual hay al menos una norma jurídica de uno de los dos sistemas que implica la comisión de un delito en el otro], los órdenes o sistemas normativos le disputan la hegemonía al orden o sistema dominante. Es decir, en caso de ampliarse su eficacia, disminuiría la del otrora absolutamente dominante, a veces hasta hacerlo desaparecer", Correas, Oscar, Teoría del derecho, op.cit., p. 176. También encontramos el "pluralismo jurídico comunitario" de Wolkmer, cuya característica central y definitoria es su autonomía en relación con el estado y la construcción normativa a partir de una democracia formada desde una subjetividad colectiva, Wolkmer, Antonio Carlos, Pluralismo jurídico. Fundamentos de una nueva cultura del derecho, trad. David Sánchez Rubio, Sevilla, MAD, 2007, p. 203.
}

42- Además de los textos de Wolkmer y Correas referidos antes, véase Melgarito Rocha, Alma Guadalupe, Pluralismo jurídico: la realidad oculta. Análisis crítico-semiológico de la relación estado-pueblos indígenas, México, UNAM-CEIICH, 2012, pp. 103-105.

43- Melgarito Rocha, Blanca Estela, "Notas acerca del estado y el derecho en la economía dependiente y retos para su destrucción revolucionaria”, en Melgarito Rocha, Blanca Estela, Sandoval Cervantes, Daniel y Caraballo Maqueira, Leonel, Derecho, lucha de clases y reconfiguración del capital en Nuestra América, Buenos Aires, Consejo Latinoamericano de Ciencias Sociales, 2018. 
la crítica jurídica, como crítica estructural radical del derecho y la sociedad capitalista, sino también en su papel positivo, que consiste en la visibilización y articulación de las praxis jurídicas anticapitalistas, y su distinción de las prácticas jurídicas capitalistas. En este contexto, la discusión sobre la estrategia revolucionaria y el uso táctico del derecho capitalista resulta esencial.

Así, en el análisis de la crítica jurídica acerca de la praxis revolucionaria y el discurso del derecho, la cuestión no es sobre el uso táctico del derecho moderno; sino en la distinción entre reforma y revolución, y la visibilización de las praxis jurídicas que disputan la hegemonía al régimen capitalista, al construir en medio de relaciones sociales que antagonizan con las relaciones definitorias del capitalismo -la propiedad privada de los medios de producción y la apropiación privada de la fuerza de trabajo de otros seres humanos. En este sentido, la tarea positiva de la crítica jurídica consiste en explicar como parte de los fenómenos sociales de nuestras sociedades, la emergencia de otras formas de juridicidad, de otros discursos del derecho, cuya tendencia general sea la disputa de la hegemonía. Sin duda, hasta el día de hoy se tratan de experiencias aisladas -al menos no articuladas sólidamente en el plano mundial-, cuya simple sumatoria no tiene como resultado el triunfo de la revolución; sin embargo, son experiencias cuyos elementos pueden contribuir tanto al análisis de las condiciones en que se reproduce el discurso del derecho capitalista como las formas en que, a través de la juridicidad, se puede disputar su hegemonía. En todo caso, habría que recordar que la revolución no es una cosa, sino un proceso y un conjunto de relaciones sociales en transformación permanente.

Por último, habría que cerrar recordando que tanto la tarea negativa o destructiva como la positiva de la crítica jurídica constituyen dos caras de una misma moneda, que pueden distinguirse analíticamente pero que constituyen partes interdependientes, en relación dialéctica, de un mismo proceso y de una misma postura político-académica. De tal forma que, aunque existan trabajos que enfaticen una u otra tarea, no pueden disociarlas. En este sentido, destruir el derecho y la sociedad capitalistas son tareas de la construcción de una sociedad y un derecho no capitalistas; en el mismo sentido, construir un derecho y una sociedad no capitalistas son, necesariamente, procesos que implican la destrucción de la sociedad y el derecho capitalistas. De la misma forma que la circulación y el consumo son partes del proceso de producción y el proceso de producción determina la circulación y el consumo. La dialéctica también es predicable de la crítica jurídica como fenómeno social.

\section{Bibliografía}

Alexy, Robert, El concepto y la naturaleza del derecho. Trad. Carlos Bernal Pulido. Madrid: Marcial Pons, 2008.

Alexy, Robert, Derecho y razón práctica. México: Fontamara, 2006.

Aragón, Manuel, Constitución, democracia y control, México, UNAM, 2002.

Bambirra, Vania, Dos Santos, Theotonio, La estrategia y la táctica socialistas de Marx y Engels a Lenin, México, ERA, 1980.

Benjamin, Walter, Para una crítica de la violencia y otros ensayos. Iluminacines IV. Trad. Robert J. Blatt Weinstein, Madrid, Taurus, 2001.

Bourdieu, Pierre, Poder, derecho y clases sociales. Trads. María José Bernuz Beneitez, Andrés García Inda, María José González Ordovás, Daniel Oliver Lalana. Bilbao, Desclée de Brouwer0, 2000. Braudel, Ferdinand, La historia y las ciencias sociales, Madrid, Alianza, 1999.

Capella, Juan Ramón, Fruta prohibida. Una aproximación histórico-teorética al estudio del derecho y el estado, Madrid, Trotta, 2001. 
Córdova, Arnaldo, La política de masas del cardenismo, México, ERA, 2010.

Córdova, Arnaldo, La ideología de la revolución mexicana. La formación de un nuevo régimen, México, ERA, 2003.

Correas, Oscar, Introducción a la sociología jurídica, México, Fontamara, 2007.

Correas, O., Kelsen y los marxistas, México, Fontamara, 2004

Correas, Oscar, Acerca de los derechos humanos. Apuntes para un ensayo, México, Coyoacán, 2004. Correas, Oscar, Teoría del derecho, México, Fontamara, 2004.

Correas, Oscar, "Acerca de la sociología jurídica: un ensayo de definición", Crítica jurídica. Revista Latinoamericana de Política, Filosofía y Derecho, núm. 12, 1993, pp. 43-51.

Entelman, Ricardo, "Discurso normativo y organización del poder", Crítica Jurídica. Revista Latinoamericana de Política, Filosofía y Derecho, no. 4, 1986, pp. 109-118.

Ferrajoli, Luigi, Garantismo. Una discusión sobre derecho y democracia, Madrid, Trotta, 2006.

Ferrajoli, Luigi, "Pasado y futuro del estado de derecho", Revista Internacional de Filosofía Política, no. 17, 2001, pp. 31-46.

Foucault, Michel, Vigilar y castigar. Nacimiento de la prisión, trad. Aurelio Garzón del Camino,, México, Siglo XXI, 2002.

Foucault, Michel, Historia de la sexualidad. La voluntad del saber, México, Siglo XXI, 1971.

Gilly, Adolfo, La revolución interrumpida, México, ERA, 1994.

Gramsci, Antonio, La política y el estado moderno, España, PC Biblioteca del pensamiento crítico, 2009.

Gramsci, Antonio, Notas sobre Maquiavelo, sobre la política y sobre el estado moderno. Madrid, Nueva Visión, 1980.

Hart, John M., El anarquismo y la clase obrera mexicana 1860-1931, México, Siglo XXI, 1980.

Huerta, Carla, Mecanismos constitucionales para el control del poder público, México, UNAM, 2010. Jeammaud, Antoine, "En torno al problema de la efectividad en el derecho", Crítica Jurídica. Revista Latinoamericana de Política, Filosofía y Derecho, no. 1, 1984, pp. 5-15.

Kelsen, Hans, Teoría pura del derecho. 15ª ed. Trad. Roberto Vernengo, México, Porrúa, 2007. Lefevbre, Henri, El materialismo dialéctico, elaleph.com, 1999.

Lenin, V.I., El estado y la revolución. La doctrina marxista del estado y las tareas del proletariado en la revolución, Moscú, Editorial Progreso, 1960.

León, Samuel y Marván, Ignacio, La clase obrera en la historia de México. En el cardenismo (19341940), México, Siglo XXI, 1985.

Marini, Ruy Mauro, Dialéctica de la dependencia, México, ERA, 1989.

Marx, Karl, "Sobre la cuestión judía". Jaramillo, R. (Ed.). Escritos de juventud sobre el derecho. Textos 1837-1847, Barcelona, Anthropos, 2008.

Marx, Karl, El capital. Crítica de la economía política. Tomo I, México, Siglo XXI, 1999.

Marx, Karl y Engels, Friedrich, La ideología alemana, Trad. Wensceslao Roces. México: Ediciones de Cultura Popular, 1974.

Melgarito Rocha, Alma Guadalupe, "Notas para un uso alternativo del derecho: el proceso penal del anarquista insurreccionalista mexicano Mario Antonio López Hernández", pp. 157-183, en Correas, Oscar; Melgarito Rocha, Alma y Sandoval Cervantes, Daniel, Criminalización de la protesta social y uso alternativo del derecho, México, UNAM-CEIICH-DGAPA/Coyoacán, 2014.

Melgarito Rocha, Alma Guadalupe, Pluralismo jurídico: la realidad oculta. Análisis crítico-semiológico de la relación estado-pueblos indígenas, México, UNAM-CEIICH, 2012.

Melgarito Rocha, Blanca Estela, "Notas acerca del estado y el derecho en la economía dependiente y retos para su destrucción revolucionaria", en Melgarito Rocha, Blanca Estela, Sandoval Cervantes, Daniel y Caraballo Maqueira, Leonel, Derecho, lucha de clases y reconfiguración del capital en Nuestra América, Buenos Aires, Consejo Latinoamericano de Ciencias Sociales, 2018. 
Melgarito Rocha, Blanca Estela, "La criminalización de la protesta y el modelo civilizatorio moderno en América Latina. El caso de Minera San Xavier y Pedro Rebolloso", pp. 49-97, en Correas, Oscar; Melgarito Rocha, Alma y Sandoval Cervantes, Daniel, Criminalización de la protesta social y uso alternativo del derecho, México, UNAM-CEIICH-DGAPA/Coyoacán, 2014.

Mora-Donato, Cecilia, El valor de la constitución normativa, México, UNAM, 2002.

Osorio, Jaime, Teoría marxista de la dependencia, México, ITACA, 2016.

Osorio, Jaime, Fundamentos del análisis social. La realidad social y su conocimiento, México, UAMFCE, 2005.

Pereyra, Carlos, Filosofía, historia y política. Ensayos filosóficos (1974-1988), México, UNAMFCE, 2010.

Sánchez Vázquez, Adolfo, Filosofía de la praxis, México, Siglo XXI, 2013.

Sandoval Cervantes, Daniel, A puntes para una crítica de la epistemología del derecho contemporáneo, Tesis doctoral, México, Facultad de Derecho, Universidad Nacional Autónoma de México, 2013. de la Torre Rangel, Jesús Antonio, El derecho como arma de liberación en América Latina. Sociología jurídica y uso alternativo del derecho, San Luis Potosí, CENEJUS, 2004.

Weber, Max, Economía y sociedad. Esbozo de sociología comprensiva, México, Fondo de Cultura Económica, 2002.

Wolkmer, Antonio Carlos, Pluralismo jurídico. Fundamentos de una nueva cultura del derecho, trad. David Sánchez Rubio, Sevilla, MAD, 2007. 